\title{
Analysis of Factors Affecting Purchase Intentions for Fashion Cultural Products
}

\author{
Yunjin Cho $\cdot$ Yuri Lee ${ }^{* \dagger}$ \\ Dept. of Textile Design, Gyeongnam National University of Science and Technology \\ *Dept. of Clothing \& Textiles, Seoul National University/Research Institute of Human Ecology, Seoul National University \\ Received December 3, 2012; Revised December 20, 2012; Accepted December 26, 2012
}

\begin{abstract}
This study conducted an empirical study on fashion cultural products that targeted foreign visitors to identify variables related to foreigners' purchase intention towards fashion cultural products. A total of 424 surveys were returned (with 393 deemed usable). The collected data was analyzed using SPSS 12.0 and AMOS 5.0 to provide the following results. The purchase intention model for fashion cultural products was verified along with an identification of a causal relationship where personal factors and attitudes lead to purchase intention. In particular, the effect of universalism and the exposure degree to Korea was greater than global-mindedness. Two factors (attitudes toward authenticity and towards aesthetic elements) exerted a significant effect on purchase intention; comparatively, the attitude toward authenticity showed a greater influence on the purchase intention.
\end{abstract}

Key words: Attitudes, Fashion cultural products, Foreign visitors, Purchase intention

\section{Introduction}

Cultural products include textiles, wood, ceramics, glass, and metal; embody aesthetic features and production technologies that are deeply enmeshed in artisans' local traditions (Littrell \& Dickson, 1999). Thus, cultural products that are region-specific can have a competitive advantage (Pugh \& Wood, 2004). There is a growing and substantial literature on the significance of cultural products and their impact on local economies (Kim \& Littrell, 1999, 2001; Lee \& Littrell, 2003, 2006; Swanson \& Horridge, 2002, 2004; Xie et al., 2012; Wilkins, 2011).

Cultural products represent and convey economic, social, and cultural values of a local culture and may lead to the development of products that greatly satisfy tourists' desires for mementos (Klamer, 2001). Further, cultural products have been attracting much attention recently with the expansion of consumption due to the

${ }^{\dagger}$ Corresponding author

E-mail: yulee3@snu.ac.kr rapidly increasing numbers of overseas tourists. Shopping is an important activity for people who visit foreign countries (Kent et al., 1983; Kim \& Littrell, 1999; Turner \& Reisinger, 2001). Cultural products are universally associated with tourism as they are commercial products purchased to remind the traveler of the tour experience (Swanson \& Horridge, 2006).

Alternatively, the cultural product market is significant because of the large potential of Internet shopping in the future. Especially, newly developed websites provide evidence of cross-border commerce between artisans (Jordan, 2000). A growing number of websites are being developed to promote cultural products made by artisans around the world, allowing consumers to shop for these products without having to visit foreign countries ("China's traditional craft shop", 2009; Lee \& Littrell, 2003, 2005; Lee et al., 2009). Online sales of such products have increased globally, and sales are estimated to reach 22 billion USD in the United States alone and 0.28 trillion USD worldwide (Lee \& Littrell, 2006). Hence, it is impor-

(C) 2013, The Korean Society of Clothing and Textiles. All rights reserved. 
tant to conduct a systematic analysis of the purchase intentions and other relevant factors of foreign visitors regarding cultural products.

Cultural products are especially significant in the Korean fashion industry. With the emergence of the World Trade Organization (WTO) and the advance of information and communication technologies, the scope of globalization is expanding. As a result, the global market has become fiercely competitive, and companies are focusing on developing global marketing strategies to guarantee higher profits. One of the critical issues for individual companies or countries in developing an effective economic strategy is to consider the specific cultural attributes of the given country. Thus, even the fashion industry can generate high added value by utilizing cultural attributes in marketing. Considering these changes, the purpose of this study, which is to identify variables related to purchase intentions for fashion cultural products, will be more pertinent.

\section{Literature Review}

\section{Theoretical Frameworks}

The Engel, Kollatt, and Blackwell (EKB) (Engel et al., 1973) model of consumer behavior served as a theoretical framework for proposing relationships between the variables expected to influence purchasing behavior of fashion cultural products. A framework of the EKB model asserts that, when making a decision, a consumer typically goes through seven major stages: need recognition, search for information, pre-purchase evaluation of alternative, purchase, consumption, postconsumption evaluation, and divestment (Blackwell et al., 2006). The model postulates that the decisionmaking process of consumers is affected by external variables in the form of either environmental influences (e.g., culture, social class, family) or individual differences (e.g., values, personality, knowledge). This model has been applied to tourism shopping (Fodness \& Murray, 1999; Kim \& Littrell, 1999). This study focuses on the stage of pre-purchase evaluation of alternative. According to the research (Blackwell et al., 2006), evaluation of alternative includes relationships between belief about products, attitude, and intention. This stage also is influenced by individual variables. In addition to the EKB model, Fishbein's (1967) attitude model was used to define the concept of belief and attitude toward fashion cultural products. In present study, consumers' general characteristics such as individual variables (universalism, world-mindedness, and degree of exposure to Korea) are expected to influence attitude toward fashion cultural products (a combination of evaluative criteria and beliefs) and intention to purchase them.

\section{Purchasing Fashion Cultural Products}

Buying souvenirs is important to tourists as tangible evidence of their travel experience (Littrell et al., 1994), and selling souvenirs contributes to the viability of the retail trade in many tourism destinations (Jansen-Verbeke, 1994). Therefore, tourism shopping has drawn increasing academic attention in recent years (Hu \& Yu, 2007).

Some researchers have focused on the sentimental or other values of souvenirs than practical ones for tourists (Gordon, 1986; Shenhav-Keller, 1993). In another approach, several studies have examined tourists' typologies in order to define meaningful market segmentation (Anderson \& Littrell, 1995; Littrell et al., 1994; Swanson \& Horridge, 2006).

Several studies have focused on the authenticity of souvenirs (Asplet \& Cooper, 2000; Littrell et al., 1993; Yu \& Littrell, 2003). Littrell et al. (1993) examined the relationship between travel styles and attitudes toward the authenticity of craft items, while Asplet and Cooper (2000) focused on the importance of New Zealand's targeting of indigenous craft items that are characteristic of the island nation. Yu and Littrell (2003) focused on the relationship between the authenticity of craft items and traveling styles. Swanson and Timothy's recent research (2012) investigated souvenirs from four broad vantage points, such as historical perspectives on souvenirs research, souvenirs as messengers of meaning, souvenirs as tradable commodities and the commodification of souvenirs and handicrafts. Interestingly, Xie et al. (2012) confirmed that tourists perceive modern design combined with indigenous 
markers to be more authentic than traditional design.

Kim and Littrell $(1999,2001)$ and Turner and Reisinger (2001) reported empirical analyses of souvenir-purchasing behavior of tourists. Kim and Littrell (1999) investigated the causal relationships between individual characteristics, traveling styles, attitudes toward souvenirs, and purchase intentions. Kim and Littrell (2001) also compared two situations-whether a buyer uses the item himself/herself or gifts it to another person-to examine how purchasing behavior differs in these situations for each product type. Moreover, Turner and Reisinger (2001) examined the relationship between the satisfaction level of the consumer and demographic characteristics, product types, and product properties.

There are also a number of studies on souvenir shops. Swanson and Horridge $(2002,2004)$ examined the relationship between tourists' perception of these shops and their purchasing behavior. Recently, the focus of studies has moved from souvenirs to cultural products; this focus also sheds light on the cultural products sales that take place online (Lee \& Littrell, 2003, 2005, 2006). Lee and Littrell (2003) confirmed the growth potential of Internet sales of cultural products by conducting an analysis of Internet websites. Lee and Littrell (2005) focused on the behavior of customers purchasing cultural products online, examining the influence on purchasing behavior of the customers' Internet shopping values and their beliefs about websites that sell cultural products. In 2006, Lee and Littrell used questions related to cultural global viewpoints and values, referring to the studies of cultural creations by Ray and Anderson (2000). According to them, a person with a strong interest in cultural creations had positive attitude toward cultural products and their sales on websites. Recently, Abendroth (2011) examined the effect of the on-line availability of souvenirs, which extends the purchase opportunity to beyond the trip's end. <Table $1>$ is a summary of related studies.

\section{Universalism}

Value is a cognitive expression of the most basic and fundamental individual demands and goals. Since
Table 1. Cultural product research

\begin{tabular}{c|c}
\hline \hline Subject & Researcher \\
\hline Meaning of souvenirs & $\begin{array}{c}\text { Gordon (1986) } \\
\text { Shenhav-Keller (1993) }\end{array}$ \\
\hline Souvenir purchasers & $\begin{array}{c}\text { Anderson and Littrell (1995) } \\
\text { Littrell et al. (1994) } \\
\text { Swanson and Horridge (2006) }\end{array}$ \\
\hline Authenticity and souvenirs & $\begin{array}{c}\text { Asplet and Cooper (2000) } \\
\text { Littrell et al. (1993) } \\
\text { Xie et al. (2012) }\end{array}$ \\
\hline Tourist and retailer & $\begin{array}{c}\text { Swanson and Horridge (2002) } \\
\text { perceptions }\end{array}$ \\
\hline & Kwanson and Horridge (2004) \\
\hline Purchase intention & Kim and Littrell (1999) \\
& Yu and Littrell (2003) \\
& Wilkins (2011)
\end{tabular}

values play an important role in forming an individual's decision-making process, they have been studied as significant factors in understanding individual behaviors (Rokeach, 1973). Recently, the Schwartz Value Scale (SVS) for measuring values is receiving an increasing amount of attention. Schwartz and Bilsky $(1987,1990)$ explained the structural relationship between the ultimate value and the instrumental value, which was suggested by Rokeach, by dividing it into motivational domains of pleasure, safety, ego direction, constrained agreement, sociability, and maturity. Moreover, Schwartz (1994) applied 10 value types to a sample of 97 individuals from 44 countries for investigating the universal values that can be applied to diverse cultures. Blackwell et al. (2006) suggest that the SVS is highly influential in marketing and other behavioral science studies. Moreover, this value-measuring device is suitable for the present study because its validity has been confirmed in previous studies when applied to several different countries. Hence, this study uses the SVS as a value-measuring device for overseas consumers. The universal value factor predicts the souvenir-purchasing intentions of the sample consumers, who were visiting other countries at the time of the study. Universalism, which includes the welfare of human beings and understanding the nature, right perception, tolerance, and protection of humans, pursues a universal value that transcends individuals' egos. It is conjectured that such universal- 
ism as a value affects attitudes toward a souvenir that holds specific characteristics of another culture.

\section{World-mindedness}

The opinions that foreign visitors have regarding other cultures can affect their attitudes and intentions toward purchasing souvenirs. Kim and Littrell's studies $(1999,2001)$ confirmed that the attitude toward a certain foreign culture is a significant and meaningful variable that affects souvenir-purchasing intentions. Bhawuk and Brislin (1992) developed an Intercultural Sensitivity Inventory (ICSI), focusing on the importance of intercultural communication in the business domain. The ICSI consists of individualism, collectivism, flexibility, and openness. Flexibility and openness significantly affect the efficiency of individuals in overseas business. Flexibility is relevant to specific social activities, and openness is related to the response toward a foreign culture, as measured by opinions about international marriage, preference for cultural craft items, and other issues in Bhawuk and Brislin's study (1992).

Wiseman et al. (1989) argued that value and attitude toward a certain foreign culture play an important role in communication with members of that culture. According to him, a person's viewpoint about a foreign culture affects his or her attitude toward the members of that culture, which subsequently has an important influence on mutual understanding and communication. Any view of a foreign culture is conceptualized both by a fixed image of a culture and by a global tendency. Wiseman et al. (1989) measured global tendency using six measurement factors regarding the foreign travelers' likelihood for immigration, pursuing of global citizens, and other activities.

\section{Degree of Exposure to Korea}

Several studies have used the extent of exposure to foreign countries' cultures as an important variable affecting foreigners' attitudes to the countries they visit (Kim \& Choi, 2005; Oh et al., 2003). The extent of exposure to a foreign culture contributes to building an image about the country, which in turn affects the attitude toward buying souvenirs. Thus, the extent of exposure to a foreign country plays an important role in examining the purchase intentions of tourists when they actually visit the country. As a similar example, Kim and Littrell's study (2001) uses a sample of American women who have traveled to Mexico in the past; the extent of their exposure to the foreign culture was measured by their knowledge of Mexican culture, and the number of trips to Mexico. According to the study results, greater travel experience had a negative effect on the intention to purchase souvenirs. What this study means by foreign country, using Korean cultural products as stimuli, is Korea.

\section{Attitudes toward Fashion Cultural Products}

Attitudes toward fashion cultural products were measured by Fishbein's (1967) multi-attribute attitude model. According to Fishbein's model, two concepts in measuring product attitude are evaluative criteria $\left(e_{i}\right)$, and perception of the attributes possessed by a particular product $\left(b_{i}\right)$. Fishbein's attitude model can be expressed in equation form as:

$$
A_{B}=\sum_{i=1}^{n} b_{i} e_{i}
$$

$A_{B}:$ attitude toward the behavior

$b_{i}$ : the belief that performing behavior $B$ leads to consequence $i$

$e_{i}$ : the evaluation of consequence $i$

$n$ : the number of salient consequence

Evaluative criteria are often used to measure product attributes that a consumer finds important (Chung \& Pysarchik, 2000; Kim \& Littrell, 1999). In the present study, $b_{i}$ is the perception of a fashion cultural product's attributes and $e_{i}$ is the importance of evaluative criteria for selecting cultural products.

\section{Methods}

\section{Hypotheses}

On the basis of the above-discussed literature, a model for fashion cultural product purchase intentions is proposed. $<$ Fig. $1>$ illustrates the expected relationships between three exogenous constructs (universalism, wo- 
rld-mindedness, and degree of exposure to the foreign country) and two endogenous constructs (attitude toward fashion cultural products and purchase intention). Relationships are hypothesized as follows:

H1: Universalism will positively affect attitudes toward fashion cultural products.

$\mathrm{H} 2$ : World-mindedness will positively affect attitudes toward fashion cultural products.

H3: Degree of exposure to Korea will positively affect attitudes toward the fashion cultural products.

H4: Attitudes toward fashion cultural products will positively affect purchase intentions.

\section{Sample Design and Data Collection}

On the basis of previous studies, a questionnaire was developed. The completed questionnaire was examined by experts in the apparel industry for the validity of its contents. Subsequently, a preliminary research was conducted by six graduate students majoring in Clothing \& Textiles in Korea. According to the preliminary research results, several items of the questionnaire were corrected.

We prepared three different versions of the questionnaire utilizing back-translation procedures. First, the questionnaire was completed in Korean and then translated into English by a bilingual Korean translator fluent in both languages. It was in turn translated into Chinese by a Korean fluent in Chinese and Korean and then translated into Japanese by a Korean fluent in Japanese and Korean. The three latter versions were then translated back into Korean by different bilingual individuals who did graduate work in fashion and com- pared to the original version for accuracy. Several items were modified to improve accuracy regarding cultural differences.

Data were collected from places with large numbers of foreign visitors, including Inchon airports, language institutions, and tourist attractions. The data collection was designed to be conducted in various places in order to include foreign visitors who were travelling for different purposes. Chopsticks representing Korean traditional folk art were offered to respondents as a participation incentive. American, Japanese, and Chinese tourists were selected specifically as samples, because they constitute the majority of foreign visitors. According to the Korea Tourism Organization's research, in 2005, $44.3 \%$ of foreign visitors were Japanese, $11.4 \%$ were Chinese, and $10.7 \%$ were American. The samples for all the three countries were selected from November 13 to December 26,2006 . Five hundred questionnaires were distributed, of which 424 were collected. After excluding dishonest responses and those with a number of missing values, 393 questionnaires were used in the statistical analysis. This total sample consisted of 119 Chinese, 146 Japanese, and 118 Americans. The number of Japanese was intentionally slightly larger than those from other countries, since Japanese tourists constitute the highest percentage of foreign visitors to Korea. Therefore, the collected sample with different number of tourists from each country was used as is without correction. With regard to gender, $45.8 \%$ were men and $55.2 \%$ were women. Among the samples, $19.9 \%$ were married and $79.5 \%$ were single. As for the education level of the visitors, $57 \%$ had college degrees, implying that the education level of the sample is relatively high.

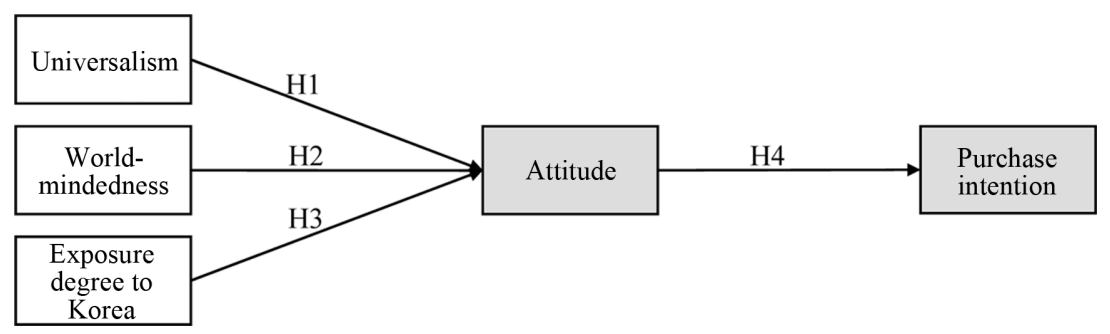

Fig. 1. Proposed model. 
The majority (67.8\%) of the Chinese sample reported an income of less than a million Korean won (KRW) per month. In contrast, only $32.8 \%$ of the American and $43.2 \%$ of the Japanese samples reported an income of less than a million KRW per month. However, considering the per capita incomes of the three countries, the rate of the Chinese sample cannot be overestimated. In the case of the American and Japanese samples, the rate of foreign visitors reporting a low monthly income was higher than expected. This was because a large portion of the samples consisted of students who had visited Korea with the intention of studying abroad.

\section{Stimuli Development}

Two product types (t-shirts, scarves) were selected as stimuli for this study because a recent study (Cho, 2007) identified these products as being particularly popular apparel choices among shoppers, based on interviews with owners of Korean cultural products shopping sites, such as museums, art galleries and street shops in Insa-dong, Namdeamun. Since this study tar- gets foreign tourists who do not have much knowledge about Korean cultural characteristics and Korean fashion cultural products, some pictures of two product types were used as stimuli. A Korean fashion designer then produced a variety of product designs for each product type. Based on focus group interview with twenty foreigners and seven Koreans, several designs with Korean characteristics were selected. In addition, fashion marketing professionals were consulted. Finally, two Korean designs for each product type were selected.

\section{Survey Description}

Cronbach's alpha was used to examine the reliability of items (Table 2). Three questions designed to measure universalism were adopted from Schwartz (1994) using a scale beginning with $1=$ very unimportant and ending with $7=$ very important. The reliability coefficient was .80 .

Five items measuring world-mindedness were adapted from previous studies (Bhawuk \& Brislin, 1992; Wiseman et al., 1989) using the scale beginning with

Table 2. Reliability of variables

\begin{tabular}{|c|c|c|}
\hline Construct & Items & Cronbach's Alpha \\
\hline \multirow{3}{*}{ Universalism } & Unity with nature & \multirow{3}{*}{0.800} \\
\hline & Protecting the environment & \\
\hline & A world of beauty & \\
\hline \multirow{3}{*}{ World-mindedness } & $\begin{array}{l}\text { Any healthy individual (regardless of race or religion) should be allowed to live } \\
\text { wherever they want to in the world. }\end{array}$ & \multirow{3}{*}{0.643} \\
\hline & It would be better to be a citizen of the world than of any particular nation. & \\
\hline & Our country should make it easier for foreigners to immigrate. & \\
\hline \multirow{2}{*}{$\begin{array}{l}\text { Degree of exposure } \\
\text { to Korea }\end{array}$} & I can speak Korean well. & \multirow{2}{*}{0.675} \\
\hline & I know Korea pretty well. & \\
\hline \multirow{3}{*}{ Authenticity } & It was made by a famous artisan or company from Korea. & \multirow{3}{*}{0.849} \\
\hline & It is handcrafted. & \\
\hline & It has a name or design related to Korea. & \\
\hline \multirow{2}{*}{ Aesthetics } & The color is appealing. & \multirow{2}{*}{0.850} \\
\hline & The design is appealing. & \\
\hline \multirow{2}{*}{$\begin{array}{l}\text { Care and carriage } \\
\text { convenience }\end{array}$} & It is easy to pack or carry with me on a trip. & \multirow{2}{*}{0.622} \\
\hline & It is easy to care for or clean. & \\
\hline \multirow{3}{*}{ Purchase Intention } & I have an intention to purchase this product to use it myself. & \multirow{3}{*}{0.955} \\
\hline & I have an intention to purchase this product as a souvenir for myself. & \\
\hline & I have an intention to purchase this product. & \\
\hline
\end{tabular}


$1=$ strongly disagree and ending with $7=$ strongly agree. With regard to questions involving international marriage and freedom of religion, the items from Bhawuk and Brislin (1992) were used, while those from Wiseman et al. (1989) were used for questions on global citizenship, freedom of residence, and the likelihood of foreign immigration. Two items were excluded, and the final reliability of the three items was .64.

The degree of exposure to Korea was measured by an interest in Korea, knowledge about Korea, and Korean-language skills. To determine the level of interest in Korea, the item that measures general knowledge about a country, which was used in Bhawuk and Brislin's study (1992), and another item regarding Korean-language skills were used in this study. One item that examines interest in Korea was also developed by the researcher. This item was excluded, and the reliability of this factor was .68 $(1=$ not at all, $7=$ totally $)$.

Items measuring evaluative criteria for souvenirs were developed by Littrell et al. (1994). Respondents were asked to rate the importance of 14 criteria when selecting fashion cultural products $\left(e_{i}: 1=\right.$ very unimportant, $7=$ very important). Respondents then viewed color photos of four fashion cultural products and indicated their perception of the presence of 14 attributes for each product $\left(b_{i}: 1=\right.$ not at all, $7=$ totally). When factor analyses with varimax rotation were performed on the calculated attitude score $\left(e_{i}\right.$ and $\left.b_{i}\right)$, a three-factor structure was confirmed. The factor accounted for $67.66 \%$ of the total variance. Three items pertaining to craftsmanship and authentic qualities were grouped as one factor (authenticity); two items involving color and design were grouped as another factor (aesthetics). Two items involving care and carriage convenience were grouped as the final factor (care and carriage convenience). Attitudes toward fashion cultural products were measured using indices derived from a combination of the importance-criteria factor $\left(e_{i}\right)$ and the perceived-attributes factor $\left(b_{i}\right)$. Since attitude scores and purchase intention for each dimension did not show a statistically significant difference among the stimuli, an average point was calculated and entered into the purchase-intention model for fashion cultural products. Three dimensions of attitudes were named as: (1) attitude toward aesthetic of fashion cultural products, (2) attitude toward authenticity of fashion cultural products, (3) attitude toward care and carriage convenience of fashion cultural products. The H4 was changed into H4-1, H4-2, and $\mathrm{H} 4-3$ because the attitudes were classified in three factors.

As for the intention to buy fashion cutural products, we developed questions about overall purchase intentions and souvenir-purchasing intentions, while using the question from Kim and Littrell's study (2001) of whether the intention is to purchase for themselves or to purchase gifts for others. The item of purchasing gifts for others was dropped, and the final reliability of this scale was .96. Purchase intention scores appeared highly consistent for four fashion cultural products and were therefore averaged.

Demographic information was obtained for sampledescription purposes. Respondents were asked about their age, nationality, marital status, education, and income.

\section{Analysis of Results}

\section{Structural Equation Modeling}

$<$ Table 3> shows the results of the seven-construct scales. Correlations between constructs for universalism, world-mindedness, the degree of exposure to Korea, and attitude toward fashion cultural products (three factors) and purchase intention were examined.

To test hypotheses for causal relationships, the AMOS program was used. Following the "Two-Step Approach" suggested by Anderson and Gerbing (1988), this study conducted a confirmatory factor analysis by entering the exogenous variables and the endogenous variables simultaneously. The Two-Step Approach refers to a method in which the comprehensive aspects of endogenous and exogenous variables within the model are examined before constructing a causal path for the model. According to the confirmatory factor-analysis results, the overall goodness-of-fit was satisfactory, with $\chi^{2}(d f=90)=137.086(p=.001), \mathrm{CFI}=.985$, $\mathrm{GFI}=.956$, and RMSEA $=.038$. This implies that the unidimensionality of all constructs used in this study 
Table 3. Correlation coefficients of research variables

\begin{tabular}{c|c|c|c|c|c|c|c}
\hline \hline & $\begin{array}{c}\text { Universalism } \\
\xi_{1}\end{array}$ & $\begin{array}{c}\text { World-mindedness } \\
\xi_{2}\end{array}$ & $\begin{array}{c}\text { Degree of exposure } \\
\text { to Korea } \\
\xi_{3}\end{array}$ & $\begin{array}{c}\text { Authenticity } \\
\text { (attitude) } \\
\eta_{1}\end{array}$ & $\begin{array}{c}\text { Aesthetics } \\
\text { (attitude) } \\
\eta_{2}\end{array}$ & $\begin{array}{c}\text { Care \& carriage } \\
\text { (attitude) } \\
\eta_{3}\end{array}$ & $\begin{array}{c}\text { Purchase } \\
\text { intention } \\
\eta_{4}\end{array}$ \\
\hline$\xi_{1}$ & 1 & & & & & & \\
\hline$\xi_{2}$ & $0.292^{* *}$ & 1 & 1 & & & \\
\hline$\xi_{3}$ & 0.019 & 0.023 & $0.183^{* *}$ & $0.217^{* *}$ & 1 & & \\
\hline$\eta_{1}$ & $0.221^{* *}$ & $0.172^{* *}$ & $0.230^{* *}$ & $0.382^{* *}$ & 1 & & \\
\hline$\eta_{2}$ & $0.218^{* *}$ & $0.167^{* *}$ & $0.189^{* *}$ & $0.469^{* *}$ & $0.412^{* *}$ & 1 & \\
\hline$\eta_{3}$ & $0.179^{* *}$ & $0.124^{*}$ & $0.216^{* *}$ & $0.634^{* *}$ & $0.431^{* *}$ & $0.325^{* *}$ & 1 \\
\hline$\eta_{4}$ & 0.075 & & & & & \\
\hline
\end{tabular}

$* p<.05, * * p<.01$

is valid (Bagozzi \& Yi, 1988). Moreover, the discriminant validity and convergent validity of each factor were also investigated. The convergent validity of the construct was examined by factor loading of the measurement index, i.e., t-value significance, as was suggested by Bagozzi and Yi (1991). According to the confirmatory-factor analysis results, the relationship between all measurement indices and constructs turned out to be significant, confirming the convergent validity of the constructs. Meanwhile, the discriminant validity examines how each factor measures distinct concepts. In this study, the discriminant validity was also confirmed in that each factor focuses on measuring different dimensions.

The following hypothesized relationships were then examined: universalism and attitude toward souvenirs (H1), world-mindedness and attitude toward souvenirs (H2), degree of exposure to Korea and attitude toward souvenirs (H3), the three dimensions of attitude toward souvenirs and purchase intention (H4-1, H4-2, H4-3). With regard to the goodness-of-fit-index, the test results on the purchase intention path model revealed $\chi^{2}(d f)$ of 196.545 (120), GFI of .946, AGFI of .924 , CFI of .978, and RMSEA of .042, providing evidence that it is overall an optimal model (Fig. 2).

\section{Hypothesis Test}

Hypothesis 1 (H1) proposed a positive relationship between universalism and attitude toward fashion cultural products. Universalism was significantly related to three dimensions of attitude toward fashion cultural products, and $\mathrm{H} 1$ was supported. That is, persons with strong universal values were more likely to hold a favorable attitude toward fashion cultural products.

Hypothesis $2(\mathrm{H} 2)$ proposed a positive relationship between world-mindedness and attitude toward fashion cultural products. World-mindedness significantly affected three dimensions of attitude toward fashion cultural products. Therefore, H2 was supported. More world-minded persons tended to hold a more favorable attitude toward fashion cultural products than did less world-minded persons.

Hypothesis $3(\mathrm{H} 3)$ proposed a positive relationship between the degree of exposure to the foreign country and attitude toward fashion cultural products. The degree of exposure to Korea significantly affected three dimensions of attitude toward fashion cultural products. Therefore, H3 was supported. This implies that when visitors have a greater exposure to Korean culture, there is a higher likelihood that they will purchase Korean fashion cultural products.

Hypothesis 4 (H4) predicted a positive relationship between attitude toward fashion cultural products and purchase intentions. The attitude toward authenticity and aesthetics of fashion cultural products positively predicted purchasing intentions for fashion cultural products (H4-1, H4-2). The attitude toward authenticity showed the strongest influence on purchase intention among three dimensions of attitude. This finding suggested that a positive attitude toward the authentic characteristics of fashion cultural products is the best predictor of purchase intentions. However, no significant relationship was found between attitudes toward care and carriage conveni-ence of fashion cultural products and purchase intentions (H4-3). In this 


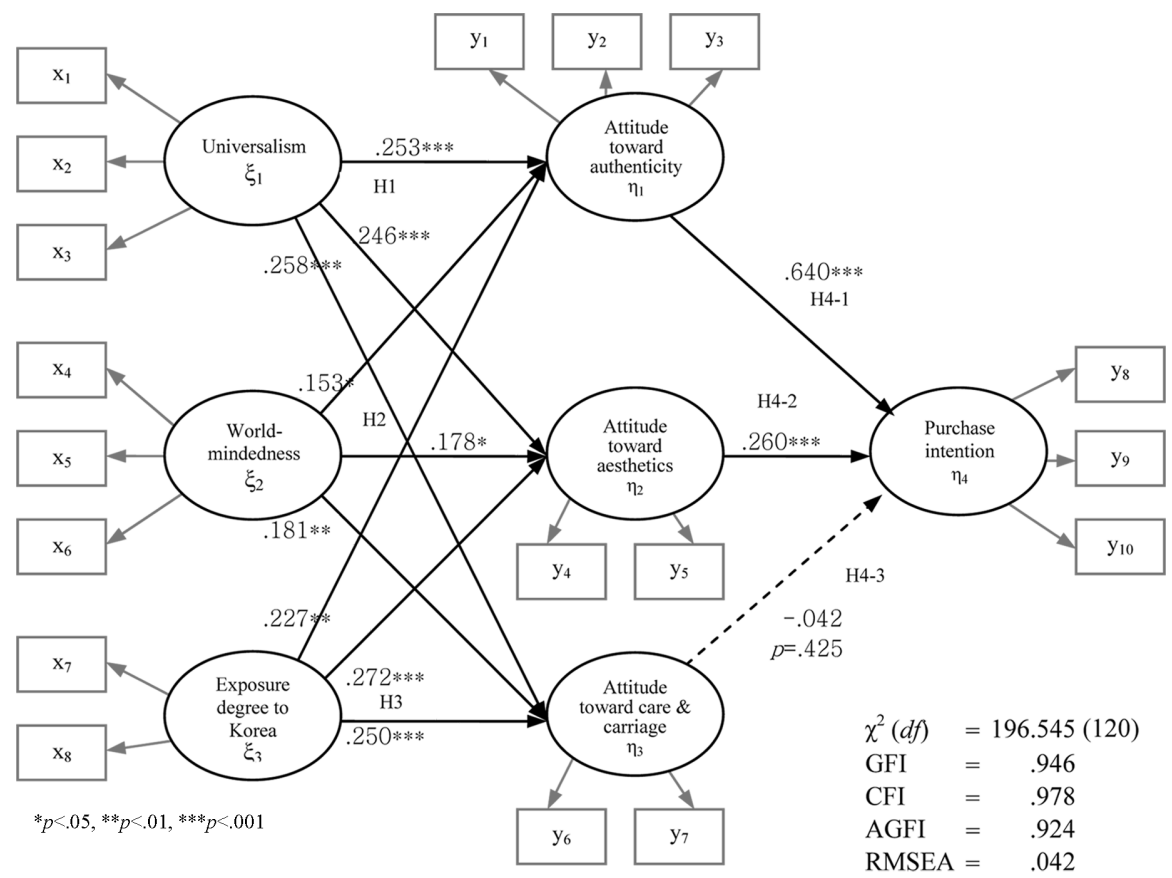

Fig. 2. Purchase intention path model.

case, $\mathrm{H} 4$ was supported only partially. Personal factors (i.e., universalism, world-mindedness, the degree of exposure to Korea) influenced the attitudes towards care and carriage convenience, but the latter did not significantly influence the purchase intention. This result is because all the stimuli used in the research were fabric products. Fashion cultural products are easier to carry and care for than those made of other materials, which distinguishes them from other products. Since a relationship between personal factors and attitude toward care and carriage convenience was identified, the attitude toward care and carriage convenience is regarded as a critical factor.

Overall it was identified that individual variables influence consumers' attitudes toward fashion cultural products, and this consumers' attitudes influence intentions to purchase them. Therefore, EKB consumer decision model was supported in purchasing fashion cultural product.

\section{Decomposition of Effects}

To substantiate the effects of the proposed model, an analysis of decomposition of effects was conducted (Table 4).

An examination of indirect effects revealed that universalism, world-mindedness, and degree of exposure to Korea all had significant positive indirect effects on purchase intentions for fashion cultural products. In particular, universalism and degree of exposure to Korea had stronger indirect effects on intentions to purchase fashion cultural products than did worldmindedness.

\section{Conclusions}

This study has attempted to test and validate a structural equation model of visitors' purchase intentions towards fashion cultural products. The purchase intention model for fashion cultural products was verified, and it was revealed that personal factors including universalism, world-mindedness, and the degree of exposure to Korea exerted significant influence. As predicted, respondents who were universal, worldminded, and familiar with Korea tended to have a favorable attitude towards fashion products with the 
Table 4. Decomposition of direct, indirect and total effects for fashion cultural products

\begin{tabular}{|c|c|c|c|c|c|c|c|}
\hline & Effect & $\begin{array}{c}\text { Universalism } \\
\xi_{1}\end{array}$ & $\begin{array}{c}\text { World-mindedness } \\
\xi_{2}\end{array}$ & $\begin{array}{c}\text { Degree of exposure } \\
\text { to Korea } \\
\xi_{3}\end{array}$ & $\begin{array}{c}\text { Authenticity } \\
\text { (attitude) } \\
\eta_{1}\end{array}$ & $\begin{array}{c}\text { Aesthetics } \\
\text { (attitude) } \\
\eta_{2}\end{array}$ & $\begin{array}{c}\text { Care \& carriage } \\
\text { (attitude) } \\
\eta_{3}\end{array}$ \\
\hline \multirow{3}{*}{$\eta_{1}$} & direct effects & $0.253 * * *$ & $0.158^{*}$ & $0.227 * *$ & - & - & - \\
\hline & indirect effects & - & - & - & - & - & - \\
\hline & total effect & $0.253 * * *$ & $0.158^{*}$ & $0.227 * *$ & - & - & - \\
\hline \multirow{3}{*}{$\eta_{2}$} & direct effects & $0.246 * * *$ & $0.172 *$ & $0.272 * * *$ & - & - & - \\
\hline & indirect effects & - & - & - & - & - & - \\
\hline & total effect & $0.246 * * *$ & $0.172^{*}$ & $0.272 * * *$ & - & - & - \\
\hline \multirow{3}{*}{$\eta_{3}$} & direct effects & $0.258 * * *$ & $0.181^{*}$ & $0.250 * * *$ & - & - & - \\
\hline & indirect effects & - & - & - & - & - & - \\
\hline & total effect & $0.258 * * *$ & $0.181^{*}$ & $0.250 * * *$ & - & - & - \\
\hline \multirow{3}{*}{$\eta_{4}$} & direct effects & - & - & - & $0.640 * * *$ & $0.260 * * *$ & -0.042 \\
\hline & indirect effects & $0.215^{* *}$ & $0.139^{*}$ & $0.206^{* *}$ & - & - & - \\
\hline & total effect & $0.215^{* *}$ & $0.139^{*}$ & $0.206^{* *}$ & $0.640 * * *$ & $0.260 * * *$ & -0.042 \\
\hline
\end{tabular}

"other culture aspects" of evaluation and liking. Moreover, these factors indirectly influenced purchase intentions. However, world-mindedness was a weaker indicator of attitudes towards fashion cultural products relative to universalism and familiarity with Korea. This finding supports other studies (e.g., Kim \& Littrell, 1999) that have found tourists' personal characteristics to be significant factors in their intentions to buy souvenirs.

Two attitudes-towards authenticity and aesthetics of fashion cultural products-exerted a significant effect on purchase intentions, but the attitude towards authenticity showed a comparatively greater influence than did the attitude towards aesthetics. A causal relationship was identified in which personal factors and attitudes led to an intention to purchase products. Personal factors positively influenced the attitude towards care and carriage convenience of fashion cultural products, but did not significantly influence the purchasing intention. This is because all the stimuli used in the research were fabric products (T-shirts and scarves). The ease of caring for and carrying fashion cultural products compared to those made of other materials distinguishes them from other products, establishing this strong relationship between personal factors and the attitude towards care and carriage convenience. Hence, the attitude towards care and carriage convenience is regarded as a critical factor.
This study identified a causal relationship between personal factors, attitudes toward fashion cultural products and purchase intentions targeting foreign visitors. In addition, methodologically, overall evaluation constructs were applied to measure attitudes. Lastly, this study would contribute to strategic aspects of the fashion industry because fashion cultural products are expected to reach out to a broader overseas market.

Despite these findings, there remain several limitations. First, a more detailed consideration of the cultural background of respondents is needed. The purchase intention model in this study was not affected by cultural contexts. However, it would be better to pay attention to the cultural background of consumers, especially in global markets. Second, the present study was limited to the United States, Japan, and China. Further research applying this model to tourists from more countries is needed. Third, this study focused on Korean cloth and apparel-related cultural products. Further investigation of other cultural products is therefore required. Fourth, further research is needed to verify the findings by testing the research models on the Internet at websites selling cultural products.

\section{References}

Abendroth, L. J. (2011). Souvenir purchase decision: Effects 
from online availability. International Journal of Culture, Tourism and Hospitality Research, 5(2), 173-183.

Anderson, J. C., \& Gerbing, D. W. (1988). Structural equation modeling in practice: A review and recommended two stage approach. Psychological Bulletin, 103(3), 411423.

Anderson, L. F., \& Littrell, M. A. (1995). Souvenir-purchase behaviour of women tourist. Annals of Tourism Research, 22(2), 328-348.

Asplet, M., \& Cooper, M. (2000). Cultural designs in New Zealand souvenir clothing: The question of authenticity. Tourism Management, 21(3), 307-312.

Bagozzi, R. P., \& Yi, Y. (1988). On the evaluation of structural equation models. Journal of the Academy of Marketing Science, 16(1), 74-94.

Bagozzi, R. P., \& Yi, Y. (1991). Multitrait-multimethod matrices in consumer research. Journal of Consumer Research, 17(4), 426-439.

Bhawuk, D. P. S., \& Brislin, R. (1992). The measurement of intercultural sensitivity using the concepts of individualism and collectivism. International Journal of Intercultural Relations, 16(4), 413-436.

Blackwell, R. D., Miniard, P. W., \& Engel, J. F. (2006). Consumer behavior (10th ed.). Orlando, FL: Harcourt College Publishers.

China's traditional craft shop launched the nationwide Internet shopping mall. (2009, June 2). China.org.cn. Retrieved June 25, 2010, from http://china.naeil.com/news/ news_view.asp?nnum $=20475$

Cho, Y. (2007). Foreign visitors' attitude toward fashion cultural products. Unpublished doctoral dissertation, Seoul National University, Seoul.

Chung, J. E., \& Pysarchik. D. T. (2000). A model of behavioral intention to buy domestic versus imported products in a confucian culture. Marketing Intelligence \& Planning, 18(5), 281-291.

Engel, J. F., Kollat, D. T., \& Blackwell, R. D. (1973). Consumer behavior (2nd ed.). New York: Holt. Rinehart. Winston.

Fishbein, M. (1967). A behavior theory approach to the relations between beliefs about an abject and the attitude toward the object. In M. Fishbein (Ed.), Readings in attitude theory and measurement (pp. 389-400). New York: John Wiley \& Sons.

Fodness, D., \& Murray, B. (1999). A model of tourist information search behavior. Journal of Travel Research, $37(3), 220-230$.

Gordon, B. (1986). The souvenir: messenger of the extraordinary. The Journal of Popular Culture, 20(3), 135-146.

Hu, B., \& Yu, H. (2007). Segmentation by craft selection cri- teria and shopping involvement. Tourism Management, 28(4), 1079-1092.

Jansen-Verbeke, M. (1994). The synergism between shopping and tourism: The Japanese experience. In W. F. Theobald (Ed.), Global tourism: The next decade (pp. 347-361). Oxford: Butterworth Heinemann.

Jordan, M. (2000, June 12). Web sites revive fading handicraft: Artisans in far-flung villages around the world fashion wares for dot-com market. Wall Street Journal, pp. B1-B12.

Kent, W. E., Shock, P. J., \& Snow, R. E. (1983). Shopping: Tourism's unsung hero (ine). Journal of Travel Research, 21(4), 2-4.

Kim, S. S., \& Choi, S. H. (2005). The influence of the KoreaJapan FIFA World Cup hosting on Korea's national image. Korea Sport Research, 16(6), 1053-1063.

Kim, S., \& Littrell, M. A. (1999). Predicting souvenir purchase intentions. Journal of Travel Research, 38(2), 153162.

Kim, S., \& Littrell, M. A. (2001). Souvenir buying intentions for self versus others. Annals of Tourism Research, 28 (3), 638-657.

Klamer, A. (2001). Social, cultural and economic values of cultural goods. Culture and Public Action, September. Retrieved April 1, 2008, from http://culturalheritage.ceistorvergata.it/virtual_library/Art_KLAMER_A_2001-Social_cultural_and_economic_values.pdf

Lee, S. E., \& Littrell, M. A. (2003). Web sites for cultural products marketing potential for US consumers. Journal of Fashion Marketing and Management, 7(4), 356-370.

Lee, S. E., \& Littrell, M. A. (2005). Global e-tailing: US consumers' intention to shop for cultural products on the Internet. International Journal of Retail \& Distribution Management, 33(2), 133-147.

Lee, S. E., \& Littrell, M. A. (2006). Marketing cultural product on the Internet: Targeting cultural creatives. Clothing and Textiles Research Journal, 24(1), 33-45.

Lee, Y., Kim, S., Seock, Y. K., \& Cho, Y. (2009). Tourists' attitudes towards textiles and apparel related cultural products-A cross-cultural marketing study-. Tourism Management, 30(5), 724-732.

Littrell, M. A., Anderson, L. F., \& Brown, P. J. (1993). What makes a craft souvenir authentic? Annals of Tourism Research, 20(1), 197-215.

Littrell, M. A., Baizerman, S., Kean, R., Gahring, S., Niemeyer, S., Reilly, R., \& Stout. J. (1994). Souvenirs and tourism styles. Journal of Travel Research, 33(1), 3-11.

Littrell, M. A., \& Dickson, M. A. (1999). Social responsibility in the global market: Fair trade of cultural products. Thousand Oaks, CA: Sage Publications. 
Oh, M. Y., Park, J., \& Jang, J. (2003). Origin effect to product imagination and purchase intention: Country image model in Korea. Korean Journal of Policy Analysis and Evaluation, 13(2), 23-49.

Pugh, C., \& Wood, E. (2004). The strategic use of events within local government: A study of London Borough councils. Event Management, 9(1/2), 61-71.

Ray, P. H., \& Anderson, S. R. (2000). The cultural creatives: How 50 million people are changing the world. New York: Harmony Books.

Rokeach, M. (1973). The nature of human value. New York: Free Press.

Schwarz, S. H., \& Bilsky, W. (1987). Toward a universal psychological structure of human values. Journal of Personality and Social Psychology, 53(3), 550-562.

Schwarz, S. H., \& Bilsky, W. (1990). Toward a theory of the universal content and structure of values: Extensions and cross-cultural replications. Journal of Personality and Social Psychology, 58(5), 878-891.

Schwartz, S. H. (1994). Are there universal aspects in the structure and contents of human values? Journal of Social Issues, 50(4), 19-45.

Shenhav-Keller, S. (1993). The Israeli souvenir: Its text and context. Annals of Tourism Research, 20(1), 182-196.

Swanson, K. K., \& Horridge, P. E. (2002). Tourists' souvenir purchase behavior and retailers' awareness of tourists' purchase behavior in the Southwest. Clothing and Tex- tiles Research Journal, 20(2), 62-76.

Swanson, K. K., \& Horridge P. E. (2004). A structural model for souvenir consumption, travel activities, and tourist demographics. Journal of Travel Research, 42(4), 372380.

Swanson, K. K., \& Horridge, P. E. (2006). Travel motivations as souvenir purchase indicators. Tourism Management, 27(4), 671-683.

Swanson, K. K., \& Timothy, D. J. (2012). Souvenirs: Icons of meaning, commercialization and commoditization. Tourism Management, 33(3), 489-499.

Turner, L. W., \& Reisinger, Y. (2001). Shopping satisfaction for domestic tourists. Journal of Retailing and Consumer Service, 8(1), 15-27.

Xie, P. F., Wu, T. C., \& Hsieh, H. W. (2012). Tourists' perception of authenticity in indigenous souvenirs in Taiwan. Journal of Travel and Tourism Marketing, 29(5), 485-500.

Yu, H., \& Littrell, M. A. (2003). Product and process orientations to tourism shopping. Journal of Travel Research, 42(2), 140-150.

Wiseman, R. L., Hammer, M. R., \& Nishida, H. (1989). Predictors of intercultural communication competence. International Journal of Intercultural Relations, 13(3), 349-370.

Wilkins, H. (2011). Souvenirs: What and why we buy. Journal of Travel Research, 50(3), 239-247. 